\title{
laborhifórico
}

ISSN 2359-6910

https://revistas.ufrj.br/index.php/lh/

ARTIGO

Recebido em 1 de junho de 2020

Aprovado em 6 de agosto de 2020

\section{Pelos caminhos do Ceará, por meio das frestas do léxico}

On Ceará pathways, via the breaches of the lexicon

DOI: https://doi.org/10.24206/lh.v6i3.35141

Expedito Eloísio Ximenes

Professor Adjunto da Universidade Estadual do Ceará, Doutor em Linguística pela Universidade Federal do Ceará, Pós-Doutor em Letras pela Universidade de São Paulo, líder do grupo de pesquisa Práticas de Edição de Textos do Estado do Ceará (PRAETECE).

E-mail: expedito.ximenes@uece.br ORCID: https://orcid.org/0000-0002-1806-5764

Ticiane Rodrigues Nunes

Professora visitante do Mestrado Interdisciplinar em História e Letras da Universidade Estadual do Ceará, Doutora em Linguística Aplicada pela Universidade Estadual do Ceará, vice-líder do grupo de pesquisa Práticas de Edição de Textos do Estado do Ceará (PRAETECE).

E-mail: tixciane@yahoo.com.br ORCID: https://orcid.org/0000-0002-8877-278X 


\title{
RESUMO
}

Ao estudarmos o léxico de uma língua adentramos por caminhos diversos da vida de uma comunidade e em suas formas de expressar as realidades. Neste artigo, fazemos uma incursão em dois momentos da sociedade cearense que se interseccionam e têm como esteio a mesma realidade, os reflexos das secas, com fito de trazer uma reflexão sobre o estudo do léxico da língua portuguesa no Brasil. A partir dessa temática, nosso corpus de estudo é composto por dois textos, um manuscrito do século XVIII em que aplicamos o método filológico de edição semidiplomática e o outro do século XXI, digitalizado e exposto em ambiente virtual do qual trasladamos. Selecionamos algumas lexias nos dois textos para explicitarmos os sentidos que nos permitiram uma digressão nos contextos de uso para percebemos as realidades refletidas por meio do léxico. Nosso referencial teórico se centra nos estudos filológicos de Bassetto (2001), Gumbrecht (2007), Picchio (1979) e Spina (1977); e lexicológicos de Abbade (2006), Oliveira e Isquerdo (1998). O estudo das lexias dos textos, possibilitou-nos um entendimento mais amplo dos textos e do entorno linguístico e extra-linguístico, estabelecendo uma conexão entre os fatos abordados nas duas realidades.

Palavras-chave: Filologia. Texto. Léxico. História. Sociedade.

\begin{abstract}
ABASTRACT
When studying the lexicon of a language, we step into different paths in the life of a community and in its ways of expressing realities. In this article we make an incursion into two moments of the Ceará society that intersect and has been the mainstay of the same reality, the reflexes of droughts. The corpus of this study consists of two texts, a manuscript from the 18th century in which we applied the philological method of semidiplomatic editing, and the other from the 21st century, digitized and displayed in a virtual environment from which we transferred. We selected some lexias in both texts to explain the meanings which allowed us to digress in the contexts of use in order to understand the realities reflected through the lexicon. Our theoretical frame of reference focuses on philological studies of Bassetto (2001),Gumbrecht (2007), Picchio (1979) and Spina (1977); and lexicologicals of Abbade (2006), Oliveira and Isquerdo (1998). The study of the lexias of the texts, allowed us a broader understanding of the texts and its linguistic and extra-linguistic aspects, establishing a connection of the facts approached in the two realities.
\end{abstract}

Keywords: Philology. Text. Lexicon. History. Society. 


\section{Considerações Iniciais: Destrancando as portas}

O passado e o presente sempre se encontram, na verdade essa classificação do tempo é apenas no plano material para se arrumar melhor a vida. Passado e presente vivem em harmonia como uma forma em espiral se entrelaçando, se misturando continuamente. Nesse sentido, Barros e Kastrup (2015) postulam que passado e presente são dimensões da vida humana que se atravessam e transformam mutuamente a cada instante. Assim, estudar uma língua é olhar para o processo de constituição contínuo em que se misturam o ontem e o hoje, é abrir as portas para caminhar sobre um chão marcado pelos sinais do ser humano, com sua história e sua cultura as quais não ficaram amarradas em nenhum lugar, mas continuam vivas e se renovam, influenciando-se, ressignificando-se nas práticas do agora.

Este artigo pretende trazer uma reflexão sobre o estudo do léxico da língua portuguesa do Brasil, especificamente do Ceará, considerando dois momentos e dois textos que muito falam da história de uma comunidade e de um povo que viveu embebido em sua cultura, trabalhando, pensando, agindo e usando a língua, para dizer e fazer conforme seus costumes, suas crenças e suas necessidades de comunicação. Essas formas de dizer, de escrever e de se expressar não foram esgotadas, pelo contrário, continuam vivas e latentes estabelecendo essa conexão, ou melhor dizendo, circulando em espiral, renovando-se e mantendo-se em perfeito equilíbrio, dissolvendo o antagonismo entre passado e presente, e evidenciando o fluxo sociocultural no qual os atores sociais vivem, convivem e se relacionam (HALL, 2006).

A partir da consciência desse fluxo social em espiral, é possível perceber que as formas lexicais são as marcas mais fortes de resistência e de preservação de uma língua e de uma cultura. Em outras palavras, através do léxico da língua conhecemos o passado, a maneira como esse passado se configurava, suas tradições, organização societária, política e ideológica, que, por sua vez, podem também ser reconhecidas no léxico do presente. O léxico constitui frestas ou aberturas que nos permitem adentrar pelas veredas da língua, conhecer os sentidos das palavras e das expressões usadas pelos sujeitos em seus contextos sociais e culturais. Não existem palavras vazias ou inocentes, todas trazem ideias, posicionamentos, intenções, sobretudo, sentidos que expressam e descortinam a identidade e a própria alma de quem as diz ou escreve.

É com este olhar que estudamos aqui dois textos, um datado no século XVIII, escrito numa pequena vila do Ceará colonial com objetivos específicos, em um contexto específico de uma realidade típica da colônia. $\mathrm{O}$ outro escrito no século XXI, cuja realidade retratada é do início do século XX, estabelecendo uma conexão com a história e as vivências do povo cearense, expostas no primeiro texto, trazendo a espiral em funcionamento em que duas fontes se entrelaçam reverberando 
uma história em processo, um passado/presente sinal de que essas duas esferas não existem separadamente, mas entrelaçadas.

A língua, sobretudo o léxico, permite-nos fazer essa conexão, ou melhor, não separar as realidades, mas observarmos um contínuo de fatos reais da vida e as formas de nomeá-los por meio de expressões linguísticas que corroboram e reverberam, no presente, o passado que marcou/marca a contemporaneidade.

Nas próximas seções, descrevemos mais detalhadamente os textos e os processos de leitura e análise utilizados para elaboração deste artigo.

\section{Metodologia: Arrumando o espaço de estudo}

O espaço de tempo que adentramos para a realização deste estudo compreende um contínuo do século XVIII ao XXI, cujas portas destrancadas nos permitem um passeio pelas terras cearenses. Primeiramente pela vila de Icó, situada na região Centro-Sul do Ceará, e posteriormente por Fortaleza, capital do estado.

O primeiro texto, um manuscrito produzido pelo Padre João Saraiva de Araújo, nomeado pelo bispo de Pernambuco para ser o cura e cuidar das almas dos moradores da pequena vila e lhes oferecer o pasto espiritual. O documento pertence ao acervo do Arquivo Histórico Ultramarino da cidade de Lisboa, e foi trazido à tona por meio do Projeto Resgate de Documentação Histórica Barão do Rio Branco criado institucionalmente em 1995. Trata-se de um requerimento escrito em Icó, no dia 20 de agosto de 1744 .

Neste artigo, apresentamos o referido texto em dois modelos de edição, a fac-similar e a semidiplomática, para essa edição usamos as normas elaboradas pelo projeto Para a História do Português Brasileiro - PHPB, que utilizamos no grupo de pesquisa Práticas de Edição de Textos do Estado do Ceará - PRAETECE ${ }^{1}$, com algumas alterações. São 16 normas, que em síntese, consiste em mantermos o texto base na forma mais conservadora possível, desenvolvendo apenas as abreviaturas, colocando em itálico e em negrito as letras desenvolvidas, enumerando as linhas de cinco em cinco, e quando necessário, acrescentamos notas de pé de página para explicarmos alguma ocorrência.

O segundo passeio é pela cidade de Fortaleza, na década de 1920. Lá vivia um bode, o Bode Ioiô, em meio às ruas da cidade convivendo com os moradores, Ioiô participava ativamente do espaço 
público, passeava pela Praça do Ferreira, ia ao cinema, à praia, visitava os cafés da cidade e era visto como um ser capaz de se candidatar a vereador e para isso foi eleito.

O texto que retrata Ioiô e a realidade em que viveu foi produzido em 2018, para compor o enredo da Escola de Samba Paraíso do Tuiuti, no carnaval de 2019 no Rio de Janeiro. As histórias retratadas em ambos os textos trazem à baila uma realidade não distante uma da outra, infiltram-se e dão continuidade aos fatos históricos e às práticas políticas e sociais que até hoje são observadas.

A seguir, apresentamos as informações arquivísticas do texto 1, seguidas dos modelos de edição adotados, afim de confrontarmos os escritos com base nas fontes originais.

\subsection{Edição fac-similar e informações arquivísticas do documento}

Nesta subseção, tratamos somente da edição fac-similar e das informações arquivísticas do texto 1 por ser este um manuscrito do século XVIII e necessitar de trato filológico para o seu melhor entendimento e localização do documento por parte de um leitor interessado. Sendo assim, segue a edição fac-símile do texto 1 : 


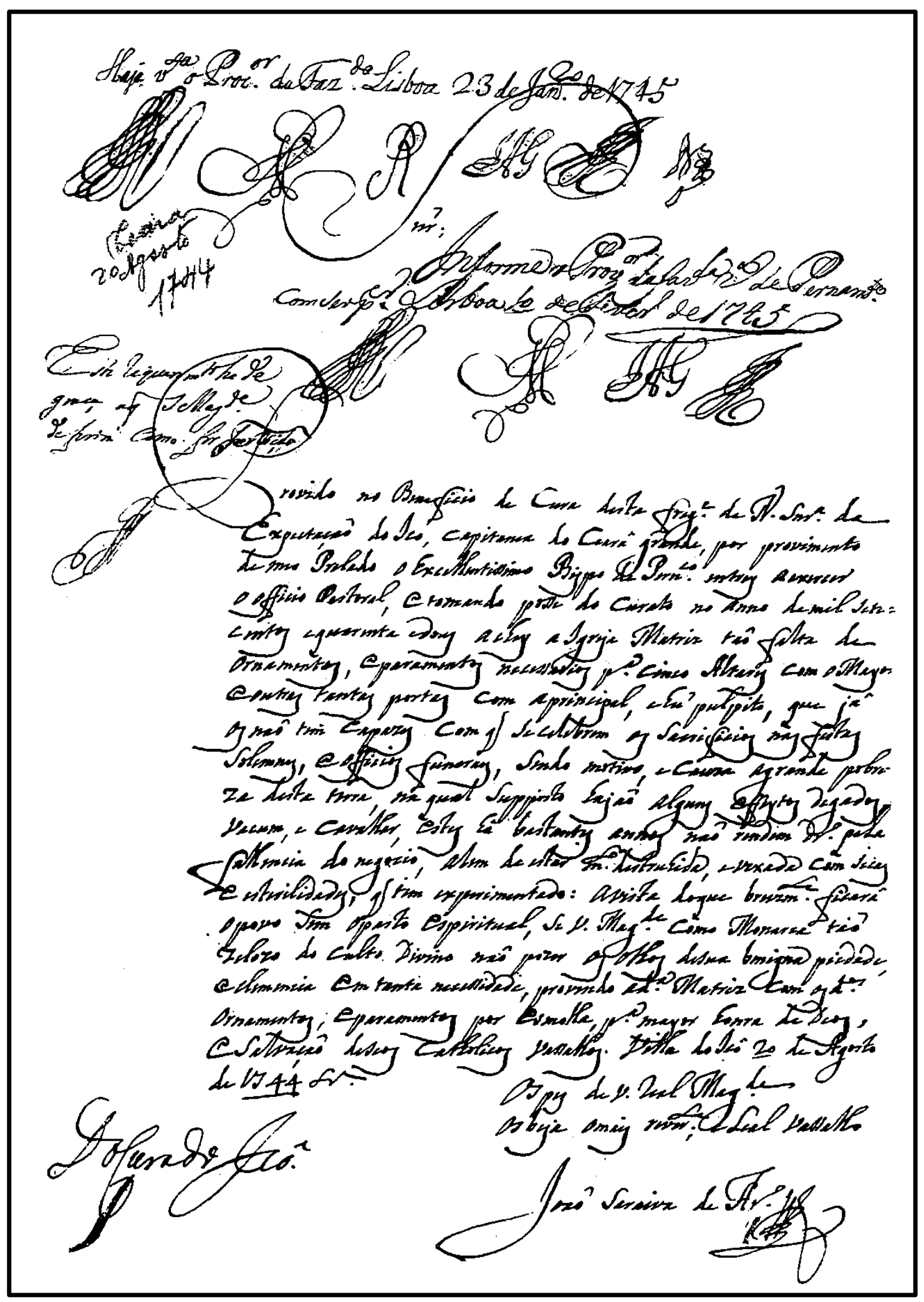

Fonte: Arquivo Histórico Ultramarino².

${ }^{2}$ Documento disponível em: https://digitarq.ahu.arquivos.pt/details?id=1266520. Acesso em: 10 maio 2020. 
Seguem informações arquivísticas do texto 1:

Arquivo Histórico Ultramarino

Conselho Ultramarino

Brasil-Ceará

1744, agosto, 20 -Icó

REQUERIMENTO docura do Icó, Pe. João Saraiva de Araújo, ao rei [D. João V] pedindo paramentos para a matriz

Caixa 04. Documento No. 237

\subsection{Edição semidiplomática e digitoscrito dos documentos}

Nesta subseção, apresentamos a edição semidiplomática do texto 1 e o digitoscrito do texto 2 .

\section{$\underline{\text { Texto } 1}$}

1 Senhor

Provido no Beneficio de Cura desta Fraguesia da Nossa Senhora da Expectaçaõ do Ico, capitania do Cearâ grande, por provimento de meo Prelado o Excellentissimo Bispo de Pernambuco entrey a exercer

5 o officio Pastoral, e tomando posse do Curato no anno de mil sete= centos equarenta edous achey a Igreja Matriz taõ falta de ornamentos, eparamentos necessarios para cinco Altares com o Mayor e outras tantas portas com a principal, ehũ pulpito que jâ os naõ tem capazes com que se celebrem os Sacrifícios nas festas

10 Solemnes, e officios funeraes, Sendo motivo, eCauza agrande pobre= za desta terra, na qual Supposto hajaõ alguns effeytos degados Vacum, e Cavallar estes há bastantes annos naõ rendem dinheiro pela fallencia do negocio, alem de estar muito destruhida, evexada com secas e esterilidades, que tem experimentado: avista doque brevemente ficará

15 o povo sem o pasto espiritual, se Vossa Magestade como Monarca taõ zelozo do culto Divino naõ pozer os olhos desua benigna piedade 
e clemencia em tanta necessidade, provendo adita Matriz com os ditos ornamentos, eparamentos por esmola, para mayor honra de Deos, eSalvação deseos Catholicos Vassalos. Villa do Icô $\underline{20}$ de Agosto 20 de $17 \underline{44}$

Os pes de Vossa real Magestade

Os beja o mais reverente, e leal vassallo

Joaõ Saraiva de Araujo

\section{Textos à margem superior}

Haja visto oProcurador daFazenda. Lisboa 23 de Janeiro de1745 [rubridas]

Informe oProvedor dafazenda real dePernambuco

com seuparecer. Lisboa 10 deAbril de1745

[Rubricas]

Ceará 20 Agosto 1744

Este requerimento he de graça aque SuaMagestade defira como for servido

Texto à margem inferior

DoCurado Icó

Em seguida, trazemos o texto 2, intitulado O salvador da Pátria, que constitui a letra do sambaenredo do carnaval de 2019 da Escola Paraíso do Tuiuti, do Rio de Janeiro. O digitoscrito do texto foi retirado do site Letras (disponível em: https://www.letras.mus.br/gres-paraiso-do-tuiuti/sambaenredo-2019-o-salvador-da-patria/\#mais-acessadas. Acesso em: 10 mar. 2019).

\section{Texto 2}

O meu Bode tem cabelo na venta

O Tuiuti me representa

Meu Paraíso escolheu o Ceará

Vou bodejar láiá, láiá

O meu Bode tem cabelo na venta

O Tuiuti me representa

Meu Paraíso escolheu o Ceará

Vou bodejar láiá, láiá 
Vendeu-se o Brasil num palanque da praça

E ao homem serviu ferro, lodo e mordaça

Vendeu-se o Brasil do sertão até o mangue

E o homem servil verteu lágrimas de sangue

Do nada, um Bode vindo lá do interior

Destino pobre, nordestino sonhador

Vazou da fome, retirante ao Deus dará

Soprou as chamas do Dragão do Mar

Passava o dia ruminando poesia

Batendo cascos no calor dos mafuás

Bafo de bode perfumando a boemia

Levou no colo Iracema até o cais

Com luxo não! Chão de capim!

Nasceu Muderna fortaleza pro bichim

Pega na viola, diz um verso pra iôiô

O salvador! O salvador!

Pega na viola, diz um verso pra iôiô

O salvador! O salvador! (Da pátria!)

Ora, meu patrão

Vida de gado desse povo tão marcado

Não precisa de dotô

Quando clareou o resultado

Tava o Bode ali sentado

Aclamado o vencedor

Nem berrar, berrou, sequer assumiu

Isso aqui, iôiô, é um pouquinho de Brasil

Nem berrar, berrou, sequer assumiu

Isso aqui, iôiô, é um pouquinho de Brasil 
O texto 2 não passou por processo de edição por ser a escrita moderna, apenas foi trasladado do ambiente virtual para o presente estudo.

O processo de análise do léxico dos dois textos consiste em fazermos o levantamento das expressões lexicais usadas que nos permitem fazer um passeio pela história social do período delimitado e estabelecermos uma comparação dos fatos representados nos textos. Percebemos que há um pano de fundo que constitui a aproximação das realidades, ou seja, as secas que, periodicamente, afetam o estado do Ceará, desde os primórdios da colonização, fenômeno climático que gera várias situações de sofrimento, sobretudo, aos mais pobres como migrações, fome, perdas dos animais, juntando-se a isso a falta de políticas públicas sérias.

Na próxima seção, apresentamos o aparato teórico que orienta nossas análises e possibilitam a discussão da temática aqui lançada.

\section{Orientações teóricas: embasando o percurso}

Nosso percurso teórico se fundamenta em duas áreas muito complementares: a Filologia e a Lexicologia. Por lidarmos com um texto manuscrito, partimos do método filológico de edição, seguido do estudo do léxico com respaldo na Lexicologia e sua abrangência histórico-cultural.

Adotamos aqui o entendimento de Filologia como o estudo integral do texto em seus aspectos formais, codicológicos, paleográficos, históricos, culturais e linguísticos. Partimos do texto como espaço de realização da língua em uso em um determinado tempo e contexto histórico cultural (SILVA NETO, 1960). O texto, por sua vez, é mais do que uma prática linguageira, é um construto social, histórico e cultural que reflete os modos de pensar e de viver de uma sociedade. Dessa forma o trabalho filológico, conforme Bassetto (2001), visa ao objetivo de reconstituição de um texto e aos esclarecimentos de aspectos relevantes a ele inerentes. Destarte, quando adentramos nas entrelinhas do texto, podemos encontrar as representações da alma humana.

Por meio do acesso e do trato do texto, podemos perscrutar alguns modos de vida de uma época, embora não tão fidedignos, pois devemos ter um olhar crítico para as fontes documentais, já que os fatos estão submersos em discursos e nenhum texto deve ser considerado inocente, no entanto, escapam-nos dados que podemos (re)conhecer como inerentes a determinados contextos.

Para Gumbrecht (2007), a Filologia concentrada no texto escrito, abrange o cuidado de um texto histórico, ou seja, “[...] a filologia se circunscreve estreitamente, para significar o cuidado de um texto 
histórico, referindo exclusivamente, a textos escritos”. (GUMBRECHT, 2007, p. 14, tradução nossa) $)^{3}$. Nesse sentido, o autor atribui três práticas à Filologia: "identificar fragmentos, editar textos e escrever comentários históricos são as três práticas básicas da filologia” (GUMBRECHT, 2007, p. 14, tradução nossa $)^{4}$.

Localizar os textos que, muitas vezes não são de fácil acesso ao público interessado como filólogos, historiadores, linguistas e antropólogos, constitui uma tarefa árdua de procura em acervos que também não são tão acessíveis; editar textos requer paciência, tempo e demandas de energias do pesquisador; fazer comentários históricos não menos. Contudo, não se esgota aí o labor filológico, essa tarefa não se restringe apenas a comentários históricos, é necessário investir em estudos linguísticos e discursivos dos textos para lhe garantir um aprofundamento de seu conteúdo, consubstanciando a função transcendente da Filologia (SPINA, 1977), em que o filólogo não se limita à materialidade textual, mas a transpõe e mergulha em universos outros, de modo a permitir que o texto possa subsidiar reflexões importantes sobre os contextos sociais, históricos e culturais. Em outras palavras, um contexto de pesquisa em que possamos fazer uma hermenêutica do texto por meio de uma leitura ampla e integral de elementos linguísticos e extra-linguísticos como defende Lamas (2009).

Para Picchio (1979), o filólogo não é um mero preparador de textos para ser entregues para outros pesquisadores interpretarem. "O filólogo sabe desde o início que seu estatuto é o de crítico, pois nenhuma constituição textual, nenhuma emenda seriam possíveis fora ou antes de uma compreensão total, de uma interpretação no sentido mais amplo e preciso do termo" (PICCHIO, 1979, p. 211-212).

Portanto, o labor filológico atravessa muitos percursos para que um texto se torne público e acessível, como também seja limpo de ruídos subjacentes quando se pretende mergulhar em sua profundidade para explicitar sentidos, fazer emergir discursos que nos levam para outras verdades. Uma das formas de se atingir a profundeza do texto é adentrar pelas frestas do léxico que expressa muitos sentidos históricos, políticos, religiosos, culturais de uma época e do contexto de uso.

Uma justificativa relevante para entendermos a representatividade dessa estrutura da língua é percebermos o quão o léxico e a cultura estão imbricados, ou seja, os limites entre léxico e cultura são imperceptíveis. A esse respeito, Silva Neto (1960, p. 47) defende que “[...] os estudos linguísticos encontravam [no léxico] o seu verdadeiro e adequado lugar como parte integrante da história da cultura [...]", já que o léxico é concebido como uma unidade da linguagem permeada por uma atitude cultural e política. Rajagopalan (2006), por sua vez, postula que o ato de nomear é uma maneira de

3 "[...] la filología se circunscribe estrechamente, para significar el cuidado de un texto histórico, referindo exclusivamente, a textos escritos". (GUMBRECHT, 2007, p. 14).

4 “[...] identificar fragmentos, editar textos y escribir comentarios históricos son las tres prácticas básicas de la filología”. (GUMBRECHT, 2007, p. 14). 
agregar, segregar e/ou interagir em sociedade, classificar e classificar-se nos mais variados contextos sociais, políticos e, acima de tudo, linguísticos, além de um modo de marcar a presença de uma ideologia e/ou cultura. Sendo assim, podemos ratificar que, o léxico comporta a parte significativa da língua e traz consigo representações sociais, políticas, coletivas, individuais e, principalmente, culturais dos indivíduos que a utilizam e a transformam (BIRDEMAN, 1981; MATORÉ, 1953).

A Lexicologia, no que lhe concerne o termo mais genérico, é o estudo das palavras que compõem uma língua, sobretudo das palavras lexicais, que têm um núcleo semântico e são geradoras de outras palavras. Tudo que existe no mundo material ou nos sentimentos do ser humano é nomeado e a forma de nomear as coisas gera um conjunto de lexias que compõem o léxico das línguas.

Já a lexia, por sua vez, é a unidade significativa do léxico de uma língua, ou seja, é uma palavra que tem significado social, cultural (ABBADE, 2006). Desse modo, de acordo com Faulstich (1980, p. 17), as lexias são unidades da língua que passaram a existir a partir de um hábito associativo, que lhe atribuiu caráter de lexicalização, de unidade significativa.

Segundo Pottier (1978), as lexias são estruturas funcionais e significativas de desempenho linguístico, que podem compor-se de um único lexema ou de uma sequência lexemática - uma palavra. Vale ressaltar que, para o autor, lexema é a unidade básica do léxico, como uma unidade de oposição entre léxico e vocabulário, cujo léxico é relacionado à língua, enquanto o vocabulário à fala. Nessa esteia, o lexema é equiparado ao morfema (= morfema léxico), ou seja, à unidade de significação, frequentemente superior à palavra. A partir dessa concepção, o autor constrói uma classificação para as lexias sobre a qual falamos mais a diante.

A partir desses esclarecimentos, é preciso compreender que léxico é o conjunto das lexias de uma língua ou de grupos específicos. O léxico representa o modo de pensar e de sentir de uma comunidade diante de seu contexto histórico, social e cultural. O léxico é um portal que se abre para o pesquisador adentrar no texto que edita ou prepara. Ao entrar no texto por meio das lexias nele registradas, é permitido ao filólogo ou a qualquer pesquisador, fazer um passeio pela história e pela vida de uma sociedade, perscrutando as instituições políticas, as expressões culturais e religiosas, as crenças, as instâncias jurídicas, os sistemas econômicos, as ideologias e os discursos do contexto de produção dos textos.

A língua, especificamente o léxico, é o registro fotográfico mais fiel que denuncia os hábitos e os costumes, os preconceitos, as valorações de uma comunidade e de seu tempo. 
Na medida em que o léxico configura-se como a primeira via de aceso a um texto, representa a janela através da qual uma comunidade pode ver o mundo, uma vez que esse nível da língua é o que mais deixa transparecer os valores, as crenças, os hábitos e costumes de uma sociedade. Em vista disso, o léxico de uma língua conserva uma estrita relação com a história cultural da comunidade [...]. (OLIVEIRA; ISQUERDO, 1998, p. 7).

Partindo do percurso teórico que considera o texto como um esteio dos estudos filológicos e o léxico como um portal de entrada no tempo para percorrer a história e as vivências do ser humano, na próxima seção, seguimos a nossa análise, passeando entre os séculos XVIII e XXI, para observarmos o que revelam as lexias da língua portuguesa acerca da realidade social e cultural do Ceará, em que fazemos uma reflexão sobre a língua engajada no seu contexto de uso.

\section{Análise dos textos: passeando pelo espaço-temporal}

Neste passeio pelos espaços-temporais subjacentes nos textos, podemos chegar à vila do Icó, adentrar à igreja matriz, de Nossa Senhora da Expectação, observar a sua descrição e ver ao seu redor uma pequena comunidade, perdida na imensidão do reinado de D. João V, que, apesar da distância de Lisboa, estava plenamente conectada ao reinado daquele monarca. A presença da monarquia era constante em todos os recantos do reino por meio de seus representantes, que, igualmente, transpunham essa presença monárquica nos textos que produziam.

O requerimento do Pe. João Saraiva de Araújo foi escrito no dia 20 de agosto de 1744, enviado para Lisboa, não se pode precisar a data, mas no dia 22 de janeiro de 1745, após cinco meses, o documento transitou pelo Conselho Ultramarino para deliberação dos conselheiros, que o encaminharam para o provedor da Fazendo Real de Pernambuco, no dia 10 de abril daquele mesmo ano. Não sabemos qual o resultado do pedido, pois não encontramos outras informações, mas avistamos atualmente uma interlocução que nos permite observá-lo e dialogar com seu repertório lexical.

Por meio do léxico usado no documento, muitas frestas são abertas para que possamos adentrar nos meados do século XVIII, na vila do Icó e sabermos que havia ali uma igreja matriz em ruínas, onde um padre zeloso do ofício pastoral pede ajuda para comprar os paramentos e ornamentos para exercer seu ministério.

O léxico do campo semântico religioso/sagrado está em evidência no texto, pois seu conteúdo parte de um religioso, mas há outras formas de registros que merecem igual destaque. Desse modo, 
selecionamos as lexias cujo uso não é mais recorrente na atualidade, pelo menos de algumas, e classificamos em três grupos de lexias, conforme a classificação de Pottier (1978).

(a) Lexias simples (formadas por apenas um item lexical): cura, curato, freguesia, prelado, púlpito, paramentos e ornamentos.

- A lexia cura refere-se ao sacerdote que cuida ou cura as almas;

- Curato é a povoação pastoreada por um cura;

- Freguesia é a extensão jurídica que corresponde à atual paróquia, no Brasil, daí vem a lexia freguês que trata de alguém que está sob a jurisdição de uma freguesia. A palavra freguês ampliou o sentido e migrou para o campo do comércio;

- Prelado é o título honorífico de certas dignidades eclesiásticas;

- Púlpito é local de onde o cura ou padre fala no momento de sua homilia;

- Paramentos sãos as vestes litúrgicas usadas pelos padres nos rituais da igreja, dentre eles túnica, estola, casula;

- Os ornamentos, por fim, são os objetos utilizados para adornar a igreja, principalmente os altares, como toalhas, mesa do altar, castiçais, velas, imagens, dentre outros objetos litúrgicos.

(b) Lexias compostas (constituídas por mais de um item lexical): ofício pastoral, festas solenes, pasto espiritual, culto divino, igreja matriz e altar maior.

- Ofício pastoral refere-se à atividade ou missão do sacerdote de evangelizar, cumprir os rituais dos sacramentos como celebrar missas, realizar matrimônios, batizados, cuidar das almas por meio das orações;

- Festas solenes são celebrações importantes do calendário litúrgico como a festa do Natal, da Páscoa, dentre outras;

- Pasto espiritual é o alimento da alma como a Eucaristia e a palavra da Bíblia emitida pelo sacerdote;

- Culto divino é a celebração da missa, as exéquias e a administração dos sacramentos;

- Igreja matriz refere-se à igreja principal ou sede de uma paróquia, no caso, de um curato;

- E altar maior é o altar principal de uma igreja, onde se celebra o culto.

(c) Lexias complexas (composições lexicais que estão no nível da frase, segundo a classificação de Pottier (1978)). Vale ressaltar que estamos considerando aqui como lexias complexas as que se compõem por um verbo em sua base, acrescida de um colocado. Seguem as lexias dessa classificação: entrei a exercer o ofício pastoral, ficará o povo sem o pasto espiritual e Os pes de Vossa real Magestade os beja o mais reverente, e leal vassallo.

- Primeiramente, encontramos a expressão entrei a exercer o ofício pastoral formada com o verbo entrar como auxiliar seguido do verbo principal. 
Nos documentos do período colonial, pelo menos até o século XIX, eram muito usadas expressões em que o verbo entrar funciona como auxiliar de um verbo principal. Por exemplo, nas expressões entrar a falar, entrar a espancar etc., essa composição indica uma ação que começa a acontecer, o que corrobora o aspecto incoativo do verbo e da ação verbal;

- Outra lexia marcante no texto em análise é ficará o povo sem o pasto espiritual, que significa ficar sem os sacramentos, sobretudo, a eucaristia, como alimento da alma. O pasto espiritual pode ser também a palavra ${ }^{5}$ a missa ou outros sacramentos da Igreja;

- Na conclusão do documento, destacamos a lexia Os pes de Vossa real Magestade os beja o mais reverente, e leal vassallo como uma forma de despedida marcada pelo discurso de grande humildade e subserviência de quem pede. O Pe. João Saraiva de Araújo estava na vila do Icó a serviço da igreja e da coroa portuguesa, diante do quadro de miséria da vila arrasada pelas secas e pela pobreza, ele se submete a um pedido, a nosso ver, ínfimo em termos financeiros, no entanto, seu discurso é muito subserviente submetendo-se a beijar os pés e não as mãos, como é mais comum ocorrer nos textos destinados à vossa majestade.

Ao percorrer as veredas do léxico, podemos encontrar informações sobre os períodos de secas que geram a pobreza da população, pois os gados vacum e cavalar que a população criava para seus sustentos, não estavam rendendo nenhum dinheiro, motivo pelo qual o cura se submete a pedir diretamente ao rei ajuda de custos para comprar os paramentos. Logo, a população não tinha condições de ajudar no mínimo e a própria igreja, se fosse possuidora de bens, perdera suas posses diante da extrema falta de chuva para manter seu rebanho vivo ou gerar alguns frutos por meio da agricultura.

Vemos também, apesar das dificuldades, a permanência da igreja no interior do Ceará como uma das práticas da monarquia para divulgar a religião católica a todos os rincões da colônia. Nesse contexto, os missionários estavam espalhados como funcionários do Estado para manter a imposição da crença como se observa nas palavras do padre no desfecho do seu requerimento:

avista doque brevemente ficará

o povo sem o pasto espiritual, se Vossa Magestade como Monarca taõ zelozo do culto Divino naõ pozer os olhos desua benigna piedade e clemencia em tanta necessidade, provendo adita Matriz com os ditos ornamentos, eparamentos por esmola, para mayor honra de Deos, e salvação deseos Catholicos Vassalos. (L. 14-19).

${ }^{5}$ Aqui palavra é empregada como sinônimo de escritura sagrada, escritos da bíblia. 
Outro elemento a chamar-nos a atenção eram as distâncias entre a metrópole Lisboa e a colônia, incluindo a vila do Icó, mas isso não era empecilho para se concretizar a força do domínio português. As correspondências demoravam tempo para atingirem seus objetivos, conforme observamos nas datas registradas nos documentos, mas circulavam pelas instâncias e chegavam ou não ao seu desfecho. Outra distância relevante a se observar é em relação à cúria e à sede do prelado de Pernambuco, pois toda a administração eclesiástica do Ceará estava sob a jurisprudência de Olinda e Recife. Somente em 1854 foi criada a lei régia pela assembleia do império com a anuência do imperador para a criação da Diocese de Fortaleza. Após a lei régia de criação da diocese, foi publicada a bula papal e o primeiro bispo do Ceará chega em 1861. Da mesma forma, política e administrativamente, a capitania do Ceará também era dependente de Pernambuco até 1699.

O texto 2 traz a letra do samba-enredo da escola Paraíso do Tuiuti escrito no português brasileiro moderno em que sobressaem marcas de regionalismos e formas afetuosas da língua comum.

Para a composição desse samba foram usadas várias lexias que caracterizam uma época histórica do Ceará e narra a história do Bode Iôiô, que faz parte da história do povo cearense e da cultura de uma época, sobretudo da capital, no início do século XX. O texto conta a saga do bode, trazido por migrantes do sertão para Fortaleza no período da seca de 1915. Aqui encontramos um ponto em comum com o requerimento do Pe. João Saraiva de Araújo em que a mesma realidade permeia os contextos, numa contínua história do Ceará marcada pelas secas e pelos desdobramentos que ela provoca. O gado vacum e cavalar da vila do Icó em 1734 morreu e a igreja matriz não tinha como comprar seus paramentos, levando o padre a se humilhar perante a coroa portuguesa para solicitar alguns recursos. O Bode Iôiô, por sua vez, trazido pelos migrantes da seca, perambulava pelas ruas de Fortaleza no início do século XX. A seca, nos dois contextos que se interpenetram, dá continuidade aos fatos e é o pano de fundo que proporciona o mote das histórias narradas.

Neste contexto urbano da então cidade de Fortaleza da década de 1920, o Bode Iôiô abre alas para a escola de samba contar e cantar seu enredo. A lexia Bode Ioiô é apenas uma janela que se abriu para aquele período, para se adentrar nele e se reconstruir uma época histórica de forma irônica, metafórica e crítica, que trouxe para o hoje uma realidade não passada, apenas modificada, continuando com outras vestes.

O carnavalesco Jack Vasconcelos faz uma espécie de cartografia por meio da palavra Bode Iôiô, que dá o comando, desencadeia e relaciona vários fatos políticos, culturais, costumes e vivências de uma cidade, de seus habitantes, num texto multimodal e literomusical em que se somam letra, rítmo, alegorias, danças, cores, movimentos diversos e, assim, o léxico vai evoluindo na avenida, trazendo 
informações políticas, culturais, linguísticas como formas que marcam a fala e a identidade do cearense, em outras palavras, a cearensidade como fala Pordeus Júnior (2003).

Como fizemos com o texto 1, relacionamos algumas lexias do texto 2 classificadas em consonância com as 3 três categorias de Pottier (1978):

(a) Lexias simples:bodejar, bichim, mafuás e retirante.

- Bodejar expressa a voz do bode ou o barulho emitido pelo caprino, mas também pode expressar gajuejar, dirigir galanteios libidinosos, de acordo com Ferreira (1999). Ou ainda emitir o bodejo, andar o galenteador barato, no encalço das cabrochas, à cata de aventura, conforme Cabral (1973). No desfile da escola de samba é visível o bodejo do bode, ou seja, a brincadeira dos amantes do carnaval cantando e dançando na Avenida Sapucaí, no Rio de Janeiro, em outras palavras, bodejando em sua crítica à realidade atual;

- A lexia bichim retrata uma forma carinhosa de nomear o bicho, ou seja, o bode. É muito característico da fala cearense chamar com afeto e carinho um animal ou uma pessoa dessa forma;

- Mafuás refere-se a parques de diversão como feiras com jogos e quermesses (FERREIRA, 1999). O bode passava o dia ruminando poesia, batendo cascos no calor dos mafuás, passava o dia passeando pelos locais públicos entre as pessoas como uma delas, além de ruminar poesias, pois o bode se juntava à boemia, aos poetas que frequentavam o café Java na Praça do Ferreira e outros locais;

- Retirante alude à situação de migração da população mais pobre do sertão para a capital. Essa lexia relaciona-se diretamente ao contexto da seca, visto que à época era comum grupos/famílias de sertanejos se deslocarem em busca de melhores condições de vida, como se fugissem da falta de água, alimento, e de condições insalubres de existência.

(b) Lexias composta: Bode Ioiô.

- A lexia Bode Ioiô nomeia um animal domesticado que perambulava pelas ruas e pelas praças da então cidade de Fortaleza, há mais de século atrás, que se tornara o centro das atenções da população à época. O Bode Iôiô simboliza a capacidade do cearense de se autoironizar, avacalhar o sistema político, pois foi capaz de tornar o bode candidato a vereador da cidade e elegê-lo como tal, em outras palavras, mais valia um bode vereador do que um demagogo qualquer. Isso reflete a brincadeira ou molecagem do cearense que ainda hoje marca a sua identidade. 
(c) Lexias complexas: tem cabelo na venta, vazou da fome, ao Deus dará, Dragão do Mar, vida de gado e povo tão marcado.

Segundo Cabra 1(1973), a lexia tem cabelo na venta refere-se ao indivíduo corajoso, destemido, que não tolera desaforo. Também representa o sujeito enérgico, vigoroso, bravo, brigão. Era isso que o bode representava para o habitante de Fortaleza, portanto, faz jus elegê-lo como seu representante;

- Vazou da fome significa que o bode era retirante, fugiu da fome no sertão para sobreviver em Fortaleza. Aqui encontramos mais uma referência à escassez de chuvas e de alimentos, que faziam até os bodes migrarem com seus donos para se estabelecerem na capital do estado. A mesma relação semântica está na lexia simples retirante, para fortalecer no texto a ideia da seca que faz muitos cearenses se retirarem do interior para a capital, ou para outras regiões do Brasil, em busca de melhores condições de vida;

- A lexia ao Deus dará, bastante conhecida e usada em qualquer contexto de dificuldade, significa ficar inteiramente sem proteção. No contexto de uso, o nordestino está jogado à própria sorte, sem proteção de alguma instituição ou de políticas públicas, submetido às consequências geradas pela seca;

- A lexia Dragão do Mar faz referência ao negro Francisco José do Nascimento, líder jangadeiro também conhecido por Chico da Matilde ou Dragão do Mar por sua atitude heróica de se recusar a desembarcar negros escravizados no porto do Mucuripe, em Fortaleza. É reconhecido por seu legado abolicionista e lutador a favor dos negros. Dragão do Mar nomeia também um centro de arte e cultura localizado na Praia de Iracema, em Fortaleza, em homenagem ao herói jangadeiro;

- Vida de gado designa uma vida sem muito amparo e cuidado, um povo desprezado, que vivia a migrar por falta de atitudes humanitárias, principalmente no período das grandes secas, quando não havia políticas públicas para manter as pessoas em seus lugares. Com as migrações, o povo partia em rebanhos pelas estradas do sertão, indo para a capital como gado tangido à procura de pasto, de oportunidades de sobrevivência. Nesse contexto, o governo criou os campos de concentração dos flagelados, na periferia de Fortaleza, para que os retirantes não chegassem ao centro ou aos bairros da pequena elite da capital. Em outro momento, os campos de concentração foram criados em várias cidades do interior, impedindo os migrantes de chegarem à Fortaleza, assim, continham a multidão afastada do centro urbano, sendo essa multidão tratada de forma desumana, como uma verdadeira vida de gado. É nítida a intertextualidade que essa lexia complexa estabelece com a música Admirável gado novo, de Zé Ramalho, para retratar e confirmar a vida de gado que pauta a existência dos menos favorecidos;

- Por fim, a lexia povo tão marcado corrobora a intertextualidade com a música de Zé Ramalho e o fato de esse povo ser marcado pela miséria, excluído 
da sociedade e dos cuidados públicos, concluindo, assim, o sentido da comparação com o gado, predestinado a uma vida dura.

No século XVIII, a seca não gerou migração, pois havia ainda pouca gente no Ceará, sobretudo, na vila do Icó, mas o gado morreu de fome, como vemos no texto do Pe. João Saraiva de Araújo. No século XX, o povo era o gado em retirada para não morrer de fome no sertão, mas era mal recebido e morria de inanição e de doenças geradas por ela nos campos de concentração no interior do Ceará ou na periferia de Fortaleza. E quando encontrava uma ajuda, migrava para a região Amazônica, para trabalhar nos seringais, ou para o Sudeste do Brasil, onde se mantinha como gado a morrer devagar e de fome um pouco por dia.

No samba-enredo da escola Paraíso do Tuiuti, em pleno século XXI, a crítica ainda tem muito sentido, porque a realidade mudou muito pouco. A maioria do povo brasileiro - principalmente de regiões menos abastecidas, nas comunidades periféricas das grandes capitais, nas aldeias indígenas, nas comunidades quilombolas e em quaisquer outras situações de pobreza - ainda segue a mesma rotina de ser marcado pelo preconceito, pelos poucos recursos que não atendem às necessidades básicas.

Em tempo de pandemia pelo Novo CoronaVírus, vemos o mesmo desprezo ao povo que sente a falta de amparo, pois faltam hospitais, atendimentos básicos e acima de tudo respeito ao povo diante de uma crise sanitária que deveria ser conduzida com dignidade. Indo de encontro às reais necessidades da população, o governo brasileiro zomba, ironiza e faz pouco caso de milhares de cidadãos e cidadãs que morrem e são jogados/as em valas comuns sem o mínimo de consideração por parte de quem deveria ser o líder da nação. Ainda continuamos a ver o povo marcado, marchando como gado nas filas quilométricas para receber algum auxílio, na iminência, muitas vezes, da contaminação para morrer ao Deus dará. Vemos que a história continua entrelaçada, reverberada nesse espiral de acontecimentos, unificando momentos que parecem não ter fim, num verdadeiro ciclo em que ontem e hoje são continuidades.

\section{Considerações finais: Entrelaçando as pontas}

Mostramos aqui dois momentos históricos do Ceará, entre os quais, conforme vimos e afirmamos neste texto, há uma continuidade dos fatos e da realidade, por isso, pensamos em uma espiral em que tudo se conecta e se toca, não havendo uma separação nítida de dois momentos históricos. Apesar de os textos serem datados com mais de 200 anos de distância, as realidades retratadas neles parecem não se distanciarem e corroboram uma realidade ainda mais atual e vivida em pleno contexto de pandemia, no século XXI. 
No texto 1, o requerimento do Pe. João Saraiva de Araújo, escrito em 1744, o vigário é motivado pela situação social de miséria para solicitar ao rei de Portugal uma ajuda para comprar paramentos e ornamentos para a igreja matriz da vila do Icó, porque a seca havia matado todo o gado, fonte de renda da igreja, ficando esta em situação difícil até para se exercer os rituais religiosos: Sendo motivo, e Cauza agrande pobreza desta terra, na qual Supposto hajaõ alguns effeytos degados Vacum, e Cavallar estes há bastantes annos naõ rendem dinheiro pela fallencia do negocio, alem de estar muito destruhida, e vexada com secas e esterilidades, que tem experimentado.

Não só a igreja estava vexada, nas palavras do padre, mas toda a população que além da falta de alimentos materiais, porque a terra não mais produzia e estava estéril pela falta de chuvas, o povo estava preste a perder o alimento ou o pasto espiritual. As fontes de alimento material já não existiam.

No texto 2, o samba-enredo da Escola Paraíso do Tuiuti, do Rio de Janeiro, seu compositor trata com ironia a história de um bode que veio do sertão do Ceará para a cidade, trazido pelos migrantes que fugiam da seca de 1915. No cenário de ambos os textos, a seca aparece como personagem central que motiva os fatos, quer seja na praticidade do cura do Icó em pedir humildemente socorro ou na crítica e ironia do carnavalesco em retratar um fato aparentemente insignificante, no entanto, profundamente marcado na história do Ceará. Nesse cenário de seca, as ruas de Fortaleza tornam-se o pasto do Bode Iôiô, que se tornou ícone na cultura cearense, viveu nas praças e nas ruas da cidade de Fortaleza e hoje está empalhado como peça do Museu do Ceará.

As duas histórias são marcadas pelo mesmo chão, cenário onde atuam personagens da vida real, vivenciando uma história que parece não ter fim, a história da seca e de suas consequências, que levam o homem do sertão nordestino a perder a esperança e a migrar pelos espaços desconhecidos.

Em 1744, o povo estava na eminência de perder o pasto espiritual e o pasto material já era escasso. A esperança do Pe. João Saraiva de Araújo estava na misericórdia e vontade de seu monarca, como homem zeloso do culto divino e de olhos piedosos e clementes, que leva o padre a beijar os seus pés. Na década de 1920, não havia monarquia para alimentar a esperança, o sertanejo arribou de sua terra seca, trazendo os pertences, entre eles um bode, que passa a ser o personagem fanfarrão que se habituou aos costumes da cidade provinciana e da elite urbana, mas a história é sustentada pelo mesmo pano de fundo.

As formas de dizer as coisas, ou seja, o léxico da língua em ambos os cenários trazem informações históricas, sociais e culturais que nos permitem um passeio pela pequena vila do Icó, situada no sertão a 365,6 $\mathrm{Km}$ de Fortaleza, e pelas ruas da capital cearense, para vivenciarmos os dois momentos entrelaçados pela mesma linha que costura as duas histórias.

Como compreendemos, o léxico é uma fresta que traz um raio de claridade para enxergarmos a sutileza dos acontecimentos, para adentrarmos em qualquer situação e conhecermos o que está velado 
nos antigos e atuais textos que preservam subjacentes alguma informação sobre os fatos. Compreendemos que o estudo filológico de um texto nos faz ter uma visão integral ou pelo menos mais completa da língua, da cultura e da história da sociedade que o produziu.

O entrelaçar das pontas se justifica pela escolha de pensarmos os dois contextos estudados como não estanques e distantes, mas como uma continuidade das ações humanas ou da ausência delas diante da realidade, sobretudo das ações de políticas sérias e humanas que fazem com que a história e a vida não tenha passado, tudo está em movimento espiral se entrelaçando e se revelando no século XXI, ou seja, mais uma face dessa história disfarçada que busca convencer de que tudo passou. 


\section{Referências bibliográficas}

ABBADE, C. M. de S. O estudo do léxico. In: TEIXEIRA, M. da C. R.; QUEIROZ, R. de C. R. de; SANTOS, R. B. dos (orgs.). Diferentes perspectivas dos estudos filológicos. Salvador: Quarteto, 2006.p. 226-240.

BARROS, R. B.; KASTRUP, V. Cartografar é acompanhar processos. In: PASSOS, E.; KASTRUP, V.; ESCÓSSIA, L da.(Orgs.). Pistas do método de cartografia: pesquisa-intervenção e produção de subjetividade. 1. ed. Porto Alegre: Sulina, 2015. v. 1. p. 52-75.

BASSETTO, B. F. Elementos de Filologia Românica: história externa das línguas. São Paulo: Universidade de São Paulo, 2001.

BIDERMAN, M. T. C. A estrutura mental do léxico. In: UNIVERSIDADE DE SÃO PAULO. Estudos de Filologia e Linguística: em homenagem a Isaac Nicolau Salum. São Paulo: Universidade de São Paulo, 1981.p. 131-145.

CABRAL, T. Dicionário de termos e expressões populares. Fortaleza: Instituto cultural do Cariri, 1973.

FAULSTICH, E. L. de J. Lexicologia: a linguagem do noticiário policial. Para uma análise estrutural de campos semânticos. Brasília: Horizonte, 1980.

FERREIRA, A. B. de H. Novo dicionário século XXI: o dicionário da língua portuguesa. 3. ed. Rio de Janeiro: Nova Fronteira, 1999.

GUMBRECHT, H. U. Los poderes de la Filología: dinámicas de una practica académica del texto. México D.F: Universidade Iberoamericana, 2007.

HALL, S. A identidade cultural na Pós-modernidade. 11.ed. Tradução de Tomaz Tadeu da Silva e Guacira Lopes Louro. Rio de Janeiro: DP\&A, 2006.

LAMAS, Ó. L. Bolonia, lafilología y venus ante elespejo. Revista Electrónica de Estudios Filológicos, p. 19-31, 2009. Disponível em: http://www.tonosdigital.es/ojs/index.php/tonos/article/view/297/206. Acesso em: 10 mar. 2020.

MATORÉ, G. La méthode em lexicologie: Domaine français. Paris: Didier, 1953.

OLIVEIRA, A. M. P. P., ISQUERDO, A. N. (orgs.) As ciências do léxico: lexicologia, lexicografia, terminologia. Campo Grande, MS: UFMS, 1998.

PICCHIO, L. S. A lição do Texto: Filologia e Literatura. São Paulo: Martins Fontes, 1979.

PORDEUS JÚNIOR, I. de A. Cearensidade. In: CARVALHO, Gilmar de. Bonito pra chover: ensaios sobre a cultura cearense. Fortaleza: Demócrito Rocha, 2003.

POTTIER, B. Linguística geral: teoria geral e descrição. Tradução de Walmírio Macedo. Rio de Janeiro: Presença, 1978. (Coleção Linguagem 7). 
RAJAGOPALAN, K. Pós-modernidade e a política de identidade. In: RAJAGOPALAN, K.; FERREIRA, D. M. M. (orgs.). Políticas em linguagem: perspectivas identitárias. São Paulo: Mackenzie, 2006. p. 61-80.

SILVA NETO, S. da. Língua Cultura e Civilização. Rio de Janeiro: Livraria Acadêmica, 1960.

SPINA, S. Introdução à edótica: crítica textual. São Paulo: Cultrix; São Paulo: Universidade de São Paulo, 1977. 